\title{
SANTAYANA, AL FIN, EN UN CONTEXTO FILOSÓFICO EUROPEO
}

\author{
SANTAYANA READ, FINALLY, \\ FROM AN EUROPEAN PHILOSOPHICAL CONTEXT
}

\section{Daniel Moreno Moreno}

Katarzyna Kremplewska, Life as Insinuation. George Santayana's Hermeneutics of Finite Life and Human Self. State University of New YorK Press, Nueva York, 2019, 288 pp., $\$ 85.00$.

La presencia de Santayana (Madrid, 1863-Roma, 1952) — don Jorge para unos, George para otros - es manifiesta en las últimas décadas, especialmente en lo que va de siglo XXI. Una presencia siempre discreta, como corresponde a quien vivió, y murió, como filósofo. "El último filósofo" lo acaba de llamar Manuel Ruiz Zamora en la entrada del dieciséis de marzo de su blog DESTINODIARIO, haciéndose eco de lo que Santayana dijo de sí mismo en el Prefacio de 1923 a una selección de sus poemas: "La filosofía no es un asunto opcional que pueda ocupar al filósofo ocasionalmente. Es su única vida posible, su respuesta diaria ante cualquier cosa. Vive pensando, y su sola emoción perpetua es que este mundo, con él mismo incluido, haya de ser el extraño mundo que es".

Digo esto porque llegan a mis manos varias novedades editoriales referidas a Santayana. En efecto, en el contexto del ambicioso proyecto interpretativo sobre las distintas religiones políticas que Ignacio Gómez de Liaño lleva a cabo en Democracia, Islam, Nacionalismo (Deliberar, 2018) dos de sus capítulos están dedicados a don Jorge. En "La clave gnóstica del puritano", da a conocer su lectura de la famosa novela de Santayana El último puritano (1935); y, en "La clave poética del cristianismo", se centra en La idea de Cristo en los evangelios (1946) y, en general, en la lectura poética que Santayana hace del cristianismo. El último libro de John Gray, Seven Types of Atheism (traducción española en Sexto Piso, 2018), por su parte, incluye a mister Santayana dentro del sexto tipo de ateísmo, "el ateísmo sin progreso", junto a Joseph Conrad. Es más, se puede decir que Santayana es el autor más influyente en este libro del profesor Gray. Finalmente, Juan Arnau parece 
tener a Santayana, por recurrir al argot pianístico, "en dedos", como prueban sus recientes referencias a Santayana en la entrevista que Cuadernos Hispanoamericanos le dedica en su número de abril, y en la reseña que ha publicado en Babelia del tres de mayo — ambas intervenciones, de 2019.

Estas notas se centrarán, con todo, en el muy meritorio libro de Katarzyna Kremplewska: Life as Insinuation. George Santayana's Hermeneutics of Finite Life and Human Self [Qué insinua la vida. La finitud y el yo humanos según George Santayana]. El mérito radica en abordar un flanco hasta ahora inédito en la bibliografía secundaria sobre Santayana. Mucho se ha escrito sobre él en el contexto de la filosofía norteamericana, de su relación con William James o de sus diferencias con John Dewey; en Estados Unidos, en MIT Press, se está publicando la edición crítica de sus obras, y varias generaciones de santayanianos sostienen el Overbeard in Seville. Bulletin of the Santayana Society. Mucho se ha escrito sobre Santayana desde España, especialmente desde que se sumaron a la nómina de santayanianos —exotéricos, los suficientes; no pocos, esotéricos- Fernando Savater y Manuel Garrido, auténticos precursores del auge del santayanismo en español, que explica el constante goteo de novedades editoriales, y la pervivencia de Limbo. Boletín internacional de estudios sobre Santayana. Pero quedaba todo un flanco por investigar: las relaciones de Santayana con la filosofía europea contemporánea, y plantear la cuestión de qué puede aportar el sistema filosófico de Santayana a las discusiones filosóficas actuales. En particular, a la finitud de la vida humana, al problema del yo tal como lo plantea la modernidad y la posmodernidad, y, en definitiva, a cómo enfrentar una vida que tiene mucho de insinuación, en el sentido de penetración-seduccióntrampa.

Una tarea ciertamente necesaria que la profesora Kremplewska — perteneciente a la Academia de Ciencias de Polonia, en calidad de profesora asistente de filosofía en el Instituto de Filosofía y Sociología - aborda con bastante suficiencia, y manejando fuentes hasta ahora inéditas. Acaso destacar, en general, el exceso de citas y de frases completas en cursiva, dada la necesidad que siente de apoyar todo lo que escribe, abrumada seguramente por lo que ha leído, y sin la perspectiva suficiente para distinguir con nitidez lo que un autor defiende y la relevancia de lo que los sucesivos intérpretes le hacen decir. Este constituye, sin duda, un rasgo encomiable dado que es indicio del trabajo que hay detrás, pero, a veces, no solo abruma al lector sino que lo envuelve en disquisiciones escolásticas. Puedo adelantar, con todo, que, a mi juicio, lo más interesante de su libro es el análisis que lleva a cabo de las notas que Santayana escribió al margen de Sein und Zeit, de Heidegger. Y que aparezcan aquí y allá autores poco frecuentes en los estudios sobre Santayana como: Adorno, 
Benjamin, Deleuze, Derrida, Foucault, Horkheimer, Husserl, Jaspers, Kolakowski, Ricouer, Sartre, Scheler o Wittgenstein. Queda abierta así una senda nueva poco transitada como invitación a próximos vagabundeos.

Dado que lo escrito sobre el yo-sujeto desde el siglo XVII hasta el siglo XX es mucho, la autora acepta partir de la interpretación del conocido autor canadiense Charles Taylor expuesta en su obra Sources in the Sefl, The Making of the Modern Identity (1989) [hay traducción española de 1996, en Paidós] para enmarcar la propuesta de Santayana que, evitando los términos yo y sujeto, prefiere hablar — siguiendo a su admirado Lucrecio_- de cuerpo, de psique y de espiritu. En cualquier caso, el punto de vista ya queda establecido: la antropología. La autora encuentra en Santayana un punto de apoyo para evitar tanto la Escila de un sujeto fuerte que impone su orden y su libertad al mundo como la Caribdis de un yo disuelto en el conjunto de influencias que lo llevan a su antojo como los restos de un naufragio. Como apunta en la frase final de la Introducción: "se puede considerar que ciertas estrategias filosóficas que debilitan al "ego" sirven para el fortalecimiento del yo más que para su disolución” (p. xix). Porque, efectivamente, el planteamiento naturalista de Santayana - que enraíza la mente en el cuerpo, y a ambos en el mundo, sin por eso eliminar la importancia de los momentos contemplativos o espirituales - es un buen salvoconducto para navegar en las procelosas aguas de la antropología moderna y posmoderna, asegurándose elementos tan importantes como la integridad y la autenticidad, un yo ni alejado y dominador del mundo ni desbordado y anulado por él, sino un yo con entidad suficiente en relación al mundo que lo circunscribe, aunque acaso ocupando un lugar modesto.

La habilidad de Kremplewska para recorrer los textos santayanianos — todo un océano en sí mismos — en busca de ese hilo de oro es destacable, así como que no pierda la orientación cuando Santayana, por ejemplo, habla de las máscaras, siguiendo el libro Soliloquios en Inglaterra y soliloquios posteriores (1922) [hay traducción castellana en Trotta, 2009]; en efecto, las máscaras tanto cubren como descubren: "¿Qué queda enmascarado y qué es desenmascarado por las máscaras? Las máscaras encubren la "naturaleza" en el sentido de realidad material; suponen una mediación salvadora-de-la-vida, dado que, para el espíritu una exposición literal a la naturaleza "sería mortal". Las máscaras desenmascaran la "naturaleza" como realidad fenoménica, simbólica, relativa a una vida concreta" (p. 79).

Sólo un mero apunte crítico hasta aquí. No me parece afortunada la expresión vitalismo contemplativo propuesta por la autora como sustituto del más común de naturalismo no reductivo para clasificar a Santayana. Siendo cierto que este último no capta a Santayana en toda su individualidad, el que propone Kremplewska focaliza 
en exceso, a mi juicio, la atención en el ser humano; ella encuentra en Santayana a un buen aliado por su fuerte componente ontológica, no meramente epistemológica, porque así encuentra un asidero firme para el yo, que le garantiza una ontología del yo; pero eso le lleva a reducir la ontología a lo que le compete al ser humano, algo que reduce considerablemente el ámbito ontológico. Kremplewska adopta el punto de vista humano en tanto que real pero olvida que la realidad, como tal, excede al animal humano y sus intereses. En otras palabras, para el universo - la materia, en términos propiamente santayanianos-, la vida cósmica es un accidente, más aún la vida del animal humano, que es un subconjunto de la vida cósmica; y lo que la vida le proponga o le insinúe al yo es algo no anecdótico, ciertamente, pero de un nivel no privilegiado, más aún los raros momentos en que el homo sapiens se olvida de que lo es. La contemplación y la vida humana son importantes, pero no para nombrar a lo real en su conjunto. Más sobre esto al final.

Donde la autora alcanza, con todo, un tono más personal, y más relevante, es cuando relaciona a Santayana con sus casi contemporáneos, con Henri Bergson (París, 1859-París, 1941) y con el algo más joven Martin Heidegger (Messkirch, 1889-Friburg, 1976). Muestra gran valentía al abordar la relación con Bergson, dado que Santayana le dedicó un brillante, y demoledor, ensayo cuando Bergson era el filósofo europeo más influyente; me refiero a "The Philosophy of M. Henri Bergson” (1913) —este ensayo verá próximamente la luz en George Santayana Ensayos de Historia de la Filosofía-. Kremplewska opta por incidir, a pesar de todo, en los puntos de contacto. En efecto, a pesar de que el enfoque bergsoniano peca, a ojos de Santayana, de antropomorfismo - como indica el título de una de sus obras más representativas, Materia y memoria —, su planteamiento es más cósmico que el del idealismo de la posmodernidad; la durè, por ejemplo, remite al flujo ahumano de la materia con más claridad que, por ejemplo, el Zeit heideggeriano, muy contaminado con la temporalidad tal como es vivida por el ser humano, ya sea auténtico, ya inauténtico. La autora concluye: "El radicalismo de Santayana enraíza en el potencial catártico y deconstructivo de las esencias y del espíritu. El radicalismo de Bergson descansa en que cada individuo sea portador de un "cono" con su propio pasado, que pueda cumplir también una función catártica y deconstructiva respecto a cualquier ficción. En cierto sentido, ambos asumen el proyecto de diseñar una filosofía destinada a evitar que los bumanos se hagan lunáticos” (p. 111).

En cuanto a Heidegger, Kremplewska reconoce honestamente que "hemos de ser conscientes desde el principio, sin embargo, de que nos encontramos ante dos filosofías técnicamente diferentes” (p. 116). Razón por la cual busca más bien afinidades que similitudes y se centra únicamente en ciertos aspectos del tratamiento 
del yo y de la filosofía de la vida, esto es, en: "la transformación sufrida por la idea del yo en ambas filosofías: desde el abandono de la fórmula cartesiana de un agente consciente y libre a la reinterpretación de Aristóteles y la disolución parcial de la "vigorosa" subjetividad occidental a favor de un yo hermenéutico, caracterizado por algo de pasividad" (p. 114). Ambos autores coincidirían en destacar la irreductibilidad ontológica del yo, considerado ya no como mero sujeto de conocimiento, puesto que los dos señalan a la realidad del yo más allá de la mera conciencia. Así, aunque el Dasein heideggeriano no coincide con la distinción santayaniana de psique-espíritu, ambos enfatizan la actitud de preocupación ante un mundo ajeno y no transparente, actitud propia de la actitud pre-reflexiva, básica y fundante, ante el mundo. Aunque ambos distinguen entre esencia y existencia, la diferencia no es entendida del mismo modo; en todo caso, apunta la intérprete, la distinción santayaniana, central en su sistema filosófico, sí que correlacionaría con la distinción heideggeriana entre lo óntico y lo ontológico (p. 118). Finalmente, aunque el yo estructuralmente temporal y dinámico, como "mente encarnada" parece agotarse en su horizonte mundano, en su ser-en-el-mundo, olvidando en cierto modo el elemento vertical, espiritual y liberador, tan importante para Santayana, ambos autores coinciden en su denuncia del aturdimiento (Santayana) o de la inautenticidad (Heidegger) en el sentido de que, a veces, nos perdemos a nosotros a mismos en las tareas diarias, en la irrelevancia de las opiniones y valores de la gente, en la vulgaridad, en definitiva. El horizonte de la muerte, sin embargo, _ en la estela del gran Séneca — resulta iluminante en ambos autores.

En definitiva, desde mi punto de vista, la pregunta heideggeriana por el Ser ya coloca al ente que interroga en primer plano, es decir, Heidegger parte de la antropología para acceder a la ontología, y eso es idealismo, en terminología de Santayana.

Finalmente, la profesora Kremplewska muestra su auténtica preocupación cuando se centra en cómo afrontar la finitud humana, es decir, cuando tematiza lo trágico. En este caso, su diálogo lo mantiene con Charles Padrón, a partir de su tesis doctoral, inexplicablemente inédita, "Reflections on Santayana and Tragic Value" (2000). El matiz diferenciador, con todo, aparece en una de las abundantes notas: "En definitiva, creo que Padrón acaso vea en Santayana mucho más del nietzscheano "humano, demasiado humano" que yo. Aunque yo admito la presencia de un importante componente nietzscheano en su pensamiento, a la luz de su opus magnum Reinos del ser, me inclino más a destacar la deuda del pensador con la tradición cristiana, sea en un contexto secular o del así llamado pos-secular" (p. 240). De ahí que Kremplewska sitúe a Santayana, sin negar la influencia de 
Nietzsche, o de Darwin, en el mediterráneo: "Santayana entiende "tomar partido" por lo clásico simplemente como un modo de expresar su distancia de las modas de su época. Su planteamiento, al expresar su gusto mediterráneo por la armonía y sus afinidades humanísticas, es naturalista, realista crítico y moderadamente racionalista, conformado por la búsqueda de la mesura” (p. 167).

Ese es el marco interpretativo desde el que el yo ha de gestionar lo trágico, esto es, el conflicto entre los hechos brutos y los valores, entre dos órdenes de valores, humanos y divinos o individuales y grupales, entre la culpa y la inocencia, o entre el saber como ignorancia y el saber desde una perspectiva más amplia. Lo trágico inunda y desborda el yo, evita el antropomorfismo, aunque no tiene por qué anularlo del todo, basta con hacerlo más humilde. Lo trágico diluye la distancia, o separación, nítida entre lo bueno y lo malo al situarnos ante alguien, o algo, malvado que también es bueno, o comparte algo de lo bueno, y ante algo bueno, o alguien bondadoso, trufado de maldad. Tras un exhaustivo, meritorio, y a veces iluminador, recorrido - con Santayana como guía - por lo que sobre lo trágico se ha dicho desde Grecia, el Romanticismo, la Modernidad y la Posmodernidad, Kremplewska sitúa a Santayana así: "A pesar de las veces que Santayana parece escéptico sobre las filosofías antropocéntricas y antropomórficas, la motivación de su propio pensamiento es antropocéntrica: de ahí que a veces se llame a sí mismo "un moralista". Esa vena socrática y humanística, seguramente no la única, acaso ni siquiera la dominante en el pensamiento de Santayana, enlaza con la seriedad y honestidad de su empresa intelectual, dirigida al bien del ser humano y a la claridad del pensamiento" (p. 193).

Santayana, no obstante, conociendo perfectamente los aspectos trágicos de la existencia — su honestidad le impedía tanto encubrirlos idealísticamente como apoyar las salidas religiosas ilusorias—, supo colocar la tragedia en el ámbito que le correspondía, el propiamente humano, nunca el ontológico, dado que, para el mundo, todo lo que ocurre lo hace sin más, sin conflicto, sin tragedia, sin héroes ni tumbas. Recordemos una de sus frases emblemáticas, tan del gusto de Fernando Savater: "Vivimos dramáticamente en un mundo que no es dramático". Ahora bien, aceptar la contingencia tiene mucho de liberación espiritual. Y ese es el aspecto que más le atrae a Kremplewska: la autonomía que Santayana reconoce al ámbito del espíritu: "la intuición de un ego invariante, una intuición de la que sin duda disfrutamos, encuentra su reflejo aquí" (p. 221), comentario en nota a la siguiente frase del texto principal: "Hemos de concluir que, aunque se puede interpretar a Santayana - aceptablemente - como cercano a las concepciones noegológicas contemporáneas, él defiende decisivamente la realidad del yo en tanto que enraizado en la preocupación, en la vida consciente" (p. 46). 
Desde luego, para los planteamientos que identifican las palabras y las cosas, mi lenguaje y mi mundo, el mundo conocido con el mundo, la experiencia humana de la naturaleza con la naturaleza, etc., y que, por tanto, hablan desde el discurso y para el discurso, ajenos a lo que queda realmente más allá, un planteamiento como el de Santayana resulta refrescante porque habla de ontología, de materia; y acuña el sentido técnico de egotismo para denunciar la absolutización del sujeto moderno -cf. El egotismo en la filosofía alemana, Biblioteca Nueva, 2014- En el primer caso, por cierto, la disolución del yo - que tanto preocupa a Kremplewska y que parece ser el motivo de rechazar esos planteamientos y abrazar los santayanianosocurre, claramente solo en el discurso; los yoes de las personas que defienden profesoralmente tales planteamientos no quedan afectados por su filosofía - no más de lo que convertirse de cristiano en musulmán pueda afectar a la fractura de rodilla del converso- - Así, la autora lleva razón cuando encuentra en Santayana a un filósofo que, en el discurso, recoge la importancia que el yo suele tener en la realidad, de modo que lo que se defiende en filosofía se acerque a lo que se vive como persona. Hasta ahí Santayana es un buen compañero de viaje, en tanto que crítico del idealismo ontológico.

Pero resulta que, en su propio planteamiento ontológico, es decir, al nivel del discurso, Santayana se esfuerza por pergeñar una ontología que, en la medida de lo posible, no sitúe al animal humano en su centro. De ahí que los cuatro Reinos del ser que Santayana distingue sean inquietantemente ahumanos: el ámbito de la materia lo es por principio, y en ella coloca Santayana al tropo que constituye la especie humana; el ámbito de la esencia incluye todos los matices imaginables e inimaginables de las cosas, junto con las casi infinitas relaciones establecidas o por establecer entre ellas; el ámbito de la verdad es un subconjunto del anterior y recoge solo las esencias que efectivamente incorpore el ámbito de la materia, en cualquier caso la verdad cabría únicamente en una mente divina, nunca en la meramente humana; el ámbito del espíritu sí que recoge las esencias caras a los yoes humanos, pero Santayana se centra precisamente —en compañía de Aristóteles, de místicos como san Juan de la Cruz y de algunos hindúes- en los momentos espirituales, aquellos en los que la mente se abre tanto que se olvida de sí misma. Y aquí Santayana resulta un compañero un tanto cruel y desasido.

Daniel Moreno Moreno

Departamento de Filosofía, IES Miguel Servet, Zaragoza dmoreno@unizar.es 